\title{
Examining success: identifying factors that contribute to research productivity across librarianship and other disciplines
}

\author{
Kristin Hoffmann, Selinda Berg, Denise Koufogiannakis
}

\begin{abstract}
While some academic librarians have embraced the role of researcher and have successfully become active researchers and authors, others have struggled to be productive in this aspect of their responsibilities. A content analysis of literature on research productivity for librarians and non-librarians was conducted in order to identify factors that have been found to affect research success. This content analysis is part of a larger study designed to develop an instrument to measure the impact of key factors on librarians' success in research. This analysis reinforces the need to identify and study those factors that are truly antecedents for librarians' research productivity, so that the academic library community can put our efforts and resources towards providing the supports that will be most helpful.
\end{abstract}

\section{Introduction}

Librarians' ability to succeed in research endeavours is becoming increasingly important. Scholarship, including participation in research and publication, is a professional responsibility for many academic librarians, particularly those in Canada and the United States. Scholarly output is a common requirement for tenure and promotion in Canadian and American academic libraries and therefore is an important component of librarians' career progression. In Australian academic libraries, research is not required for promotion and a practitioner service model prevails (McBain, Culshaw and Walkley Hall, 2013). Recent work from the United Kingdom indicates that librarians there are beginning to encourage and embrace practitioner-led research (Hall, 2010; Library and

\section{Author}

Kristin Hoffmann is Head, Research and Instructional Services at the University of Western Ontario in Ontario, Canada.

Email:khoffma8@uwo.ca

Selinda Berg is the Librarian for the Schulich School of Medicine - Windsor Program at the University of Windsor in Ontario, Canada.

Denise Koufogiannakis is Collections and Acquisitions Coordinator at the University of Alberta Libraries in Edmonton, Alberta, Canada. 
Information Science Research Coalition, 2012). Independent of research requirements for tenure or promotion, an increasing emphasis on a culture of assessment and evidence-based librarianship has contributed to greater need for librarians to conduct research. Some academic librarians have enthusiastically embraced the role of researcher and have successfully become active researchers and authors, but others have struggled to be productive in this aspect of their responsibilities.

The authors are interested in identifying the factors that contribute to the success of librarians as active researchers. Research success is generally aligned with productivity and output, and the authors are therefore interested in understanding the factors that encourage research productivity, as well as in clarifying how "productivity" has been operationalised for academic librarian researchers. As a first step in a larger project that will develop a validated research instrument to identify key factors that contribute to librarians' success in research, the authors conducted a content analysis of library and information science (LIS) and non-LIS literature to identify the range of factors to be considered, as well as patterns and themes across the factors.

The project builds on previous research by Fennewald (2008) and Kennedy and Brancolini (2012). Fennewald interviewed 38 librarians from Penn State University, and found that motivation, intellectual curiosity, and education were important factors in fostering research productivity. In contrast to Fennewald, who examined the experience of librarians at one institution, Kennedy and Brancolini surveyed a convenience sample of academic librarians from across the United States to ask them about their research experience, to understand their preparation to do research, and to assess their confidence to participate in research. The researchers found that librarians' confidence in their ability to perform specific tasks within the research process was a significant predictor of librarians' likelihood to research and to disseminate research. These two studies begin to describe what factors may contribute to the success of librarians as active researchers, and both identify a need for further research in this area.

The current project, together with these two earlier studies, brings a new perspective to the wide body of literature examining librarians' experience as researchers. To a large extent, the library literature has focused on factors that impede rather than enable librarians to conduct research. Several authors have addressed the challenges that librarians face when conducting research and the barriers that may prevent them from being productive researchers (Black and Leysen, 1994; Brown, 2001; Fox, 2007; Kennedy and Brancolini, 2012; Powell, Baker and Mika, 2002; Spring, 2014). Commonly noted challenges and barriers include time constraints, lack of support, and lack of research training or experience.

The prevalence of publications that focus on the obstacles and subsequent supports to overcome these obstacles may actually over-emphasise the challenges and underplay librarians' ability to do research. Conversations that have occurred within and outside of the published literature about research by academic librarians often suggest that the research environment for librarians is unique. Unlike disciplinary scholars in universities who identify research as a core part of 
their role, librarians are primarily oriented towards a role in service and practice. As such, librarians may require unique supports and resources for their research endeavours (Hill, 1994; McNicol, 2002). The current research study provides insight into how the literature relating to librarians converges with and diverges from research conducted outside of LIS. This will help to clarify aspects of the research environment for librarians that are or are not unique, as well as to shift our attention away from barriers found within our context towards factors that have led to research success both within our context and in others.

The library literature has many examples of resources and programmes that have been established in order to help librarians overcome these much-discussed barriers. Common resources and supports developed by libraries include:

- writing groups (Fallon, 2012; Campbell, Ellis and Adebonojo, 2012; Grant et al., 2010; Exner and Houk, 2010);

- opportunities for research skills development (Jacobs and Berg, 2013; Meadows et al., 2013; McBain, Culshaw and Walkley Hall, 2013; Schrader, Shiri and Williamson, 2012; Edwards, Jennerich and Ward, 2009);

- research leaves and release time (Jacobs and Berg, 2013; Edwards, Jennerich and Ward, 2009; Flaspohler 2009; Sassen and Wahl, 2013);

- funding (Neville and Henry, 2007).

These institutional responses to librarians' perceived barriers are commendable and are likely to have helped many librarians to be successful researchers. However, more evidence is needed to ensure that academic library communities are in fact providing the most helpful resources and supports, those that are most likely to lead to success for librarian-researchers.

\section{Research questions}

The purpose of this study was to examine the literature in order to understand the breadth of potential factors that may contribute to librarians' success in research. As such, it was necessary to clearly define a measurement of research success, and the researchers used research productivity as the key indicator. For this study, the working definition of research productivity was the completion of research activities and subsequent dissemination of research findings.

The following research questions guided the study:

- What factors have been identified in the scholarly literature as contributing to academic research productivity? To what extent was the identification of these factors based upon empirical research studies, and were outcomes measured or perceived?

- What are the similarities and differences between the success factors for academic librarians and those for non-librarians? What potential factors have not yet been studied for librarians? 


\section{Methods}

Both quantitative and qualitative content analysis methodologies were used to analyse the published literature on research productivity. While the differences between qualitative and quantitative approaches are recognised and often brought to fore of research discussions, Fink (2010) suggests that, in practice, qualitative and quantitative approaches to content analysis merge seamlessly, and the distinction between qualitative and quantitative is really quite arbitrary:

qualitative research, which tends to focus on the story, is often contrasted with quantitative research, which tends to focus on 'the numbers'. In actual fact, qualitative research uses numbers and quantitative uses stories.

(Fink, 2010, 144, 147)

Fink suggests that no matter which approach is taken, both are at play. The current research project makes use of this interplay by employing content analysis techniques that are both qualitative (textual analysis) and quantitative (enumeration of concepts).

In order to identify the literature discussing factors that contribute to research productivity, several databases were searched, including LISA, Library Literature, Scopus, Web of Science, and Google Scholar. LISA and Library Literature were chosen for their in-depth coverage of the library and information studies literature, while Scopus, Google Scholar and Web of Science were chosen to capture a wide breadth of literature from other disciplines. Publications were retrieved using the terms "(research AND (success factors OR supports)) OR research productivity". The authors completed their searches in May 2013 with no date limitations because the goal of the research was to identify all factors that have been considered to contribute to research productivity, independent of context and environment. The authors also mined their personal database of literature on librarians as researchers for publications that focused on success factors and available supports for librarian-researchers. Forward and backward cited reference searches on relevant papers were also undertaken. While the primary focus was on the literature of librarianship, papers related to the research productivity of faculty members and professionals in other disciplines were also included in order to achieve a more holistic understanding of the potential success factors. The current research did not aim to compare research productivity between librarianship and other disciplines, but rather looked to other disciplines in order to identify potential success factors that have not yet been researched within librarianship.

Full-text PDF files of all relevant articles were loaded into a Zotero database where each of the three authors could retrieve them. The articles were divided among the three authors for initial data extraction, coding, and data analysis. Each of the three authors was assigned a third of the articles to determine whether the article was related to librarians or non-librarians (faculty or other professionals) as well as whether the article reported on an empirical research study. The authors then individually analysed their assigned articles to code the success factors discussed. Many of the articles discussed multiple success factors. As a factor was identified, it was recorded using the terminology presented in the article. As subsequent articles were reviewed, factors were compared with previously 
identified factors to determine if they could be included with one of previously identified factors or if a new factor should be recorded. When all articles had been coded and all success factors had been identified, all three authors reviewed the entire list of factors to further amalgamate similar factors. The authors first individually reviewed the factors and then arrived at the final list of factors through discussion and collaborative analysis. Finally, the authors worked together to analyse thematically the list of success factors and to determine overarching categories.

Articles coded as empirical research studies were examined more closely in order to identify:

a. if the research explored a direct relationship between support factors and increased research productivity;

b. if that relationship was measured or perceived;

c. the nature of the relationship, if any existed.

The subset of articles which measured a direct relationship was also analysed to determine the discipline(s) of the study's population; the type of study, including sample size and response rate for survey studies; where the study was conducted; and the study's definition of research productivity.

\section{Findings}

\subsection{Overview of the literature found}

121 articles were identified from the searches across the databases listed above. Of these, 68 focused on the context of librarians and 53 examined the context of non-librarians. The articles focusing on librarians all pertained to the academic librarian practitioner context; no articles were identified that examined the context of library and information science faculty.

Figure 1 provides a breakdown of the publications retrieved and reviewed for this study. Of the 121 papers examined, 38 were not empirical research studies ("nonempirical research"); these were typically opinion pieces, reflections, or descriptions of research support initiatives. Of the remaining 83 papers that presented empirical research, 41 did not explore a direct relationship between success factors and research productivity ("no direct relationship"); for example, articles that studied a particular research support initiative or investigated the supports available to a group of researchers. This left a total of 42 research studies, listed in the Appendix, that explored a direct relationship between at least one success factor and increased research productivity ("direct relationship"). Of these, 11 examined factors related to librarians and 31 examined factors influencing non-librarians from various academic disciplines. 


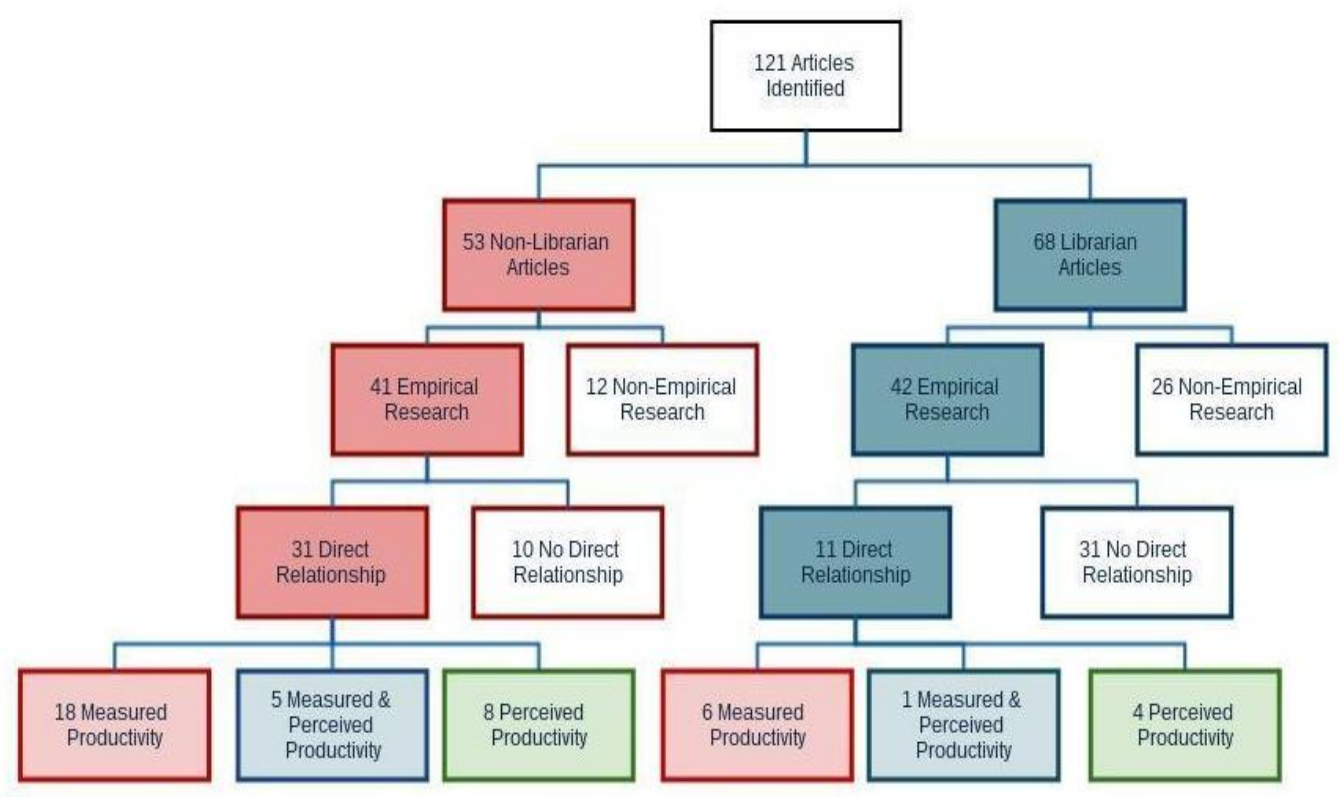

\section{Figure 1: Overview of the literature retrieved and reviewed.}

Further examination of the 42 research studies that explored a direct relationship between success factors and research productivity focused on whether the article measured a link between a factor and productivity, or whether it reported on individuals' perceptions of what affected their productivity. For example, a "measured" article might look at the correlation between a researcher's academic rank and their productivity, while an article with a "perceived" approach might ask researchers how they think their rank affected their productivity. The proportion of studies that used these approaches (measured, perceived, and blends of both) was very similar across the librarian and non-librarian subsets of research articles. Both sets of literature used measured approaches in slightly more than half of the studies examined (librarians 55\%; non-librarians 58\%); studies focused on perceived impacts were used $36 \%$ of the time for studies examining librarians and $26 \%$ for studies examining non-librarians; and $9 \%$ of the time a mixture of measured and perceived approaches were used in research on librarians, $16 \%$ for non-librarians. There were no discernible differences between the types of methodological approach within the research literature on librarians and nonlibrarians. In the majority of cases, across the studies of both librarian and nonlibrarian contexts, researchers used survey tools to gather their data.

\subsection{Productivity as defined in the literature}

While a basic working definition of research productivity was adopted in order to guide the initial stages of this study, the authors were interested in investigating how researchers defined research productivity in the literature. Research productivity was not defined consistently across the articles that were analysed, although there were commonalities among the operational definitions.

Understanding how research productivity was defined is most critical in the subset of empirical research papers that attempted to measure a relationship between certain factors and research productivity. 
All but one study that measured a direct relationship between factors and productivity included some aspect(s) of dissemination as part of their definition of research productivity. In all but one study, dissemination meant publishing articles; the exception was a study that looked at plenary presentations at a major association meeting (Cohen et al., 2012). Some articles included other forms of dissemination in addition to publishing articles, such as publishing books or presenting at conferences. Some definitions applied additional parameters of dissemination, such as a time frame for publications (for example, in the last two years or over one's career); frequency of publication, rather than a hard count of the number of publications; or a differentiation between primary or secondary author. A few papers also clustered authors into different categories of productivity: high producers, middle producers, and low producers. The one study that did not specifically include dissemination also did not explicitly define research productivity, but rather looked at librarians' self-reported participation in research as the indicator of their research success (Kennedy and Brancolini, 2012). The other measure of research productivity that was most commonly used was grants or funding received. One study also included the more general concept of "designing research projects" as a measurement of research productivity (Paul et al., 2002).

\subsection{Success factors identified}

Sixteen factors that contribute to research productivity were identified through qualitative textual analysis, as described in the Methods. The majority of these factors were explored in multiple studies. The 16 factors were grouped into three broad categories, as shown in Table 1:

1. Individual Attributes;

2. Peers and Community;

3. Institutional Structures and Supports.

Some factors straddle more than one category. For example, formal mentoring programmes are as much related to institutional structures as to peer support. However, for simplicity, each factor was assigned to one category. The distinctions between factors in Table 1 were not always observed in the articles. For example, an article may have considered time and funding together under a heading of departmental support, but for the purposes of this study's analysis, those elements were separated and coded according to these 16 factors.

The category of Individual Attributes includes factors that relate to a quality or an attribute of an individual researcher; these are factors that describe something about that person. The category of Peers and Community includes factors that relate to the networks to which an individual researcher belongs, including personal relationships and professional relationships such as mentors, coresearchers, or colleagues more generally. Lastly, the category of Institutional Structures and Supports includes supports and resources that are provided as a result of the researchers' institutional environment and context; these are not supports that the researcher personally possesses or develops. 


\begin{tabular}{|c|c|c|}
\hline Individual Attributes & Peers and Community & $\begin{array}{l}\text { Institutional Structures } \\
\text { and Supports }\end{array}$ \\
\hline Academic rank & $\begin{array}{l}\text { Collaboration } \\
\text { Includes: composition and } \\
\text { practices of research teams; } \\
\text { collaborations between LIS } \\
\text { faculty and librarians }\end{array}$ & $\begin{array}{l}\text { Access to and use of } \\
\text { resources } \\
\text { Includes: equipment; funding; } \\
\text { staff support }\end{array}$ \\
\hline $\begin{array}{l}\text { Demographics } \\
\text { Includes: age; sex; marital } \\
\text { status }\end{array}$ & $\begin{array}{l}\text { Community } \\
\text { Includes: professional } \\
\text { associations; research } \\
\text { networks; socialization }\end{array}$ & $\begin{array}{l}\text { Department/institution } \\
\text { qualities } \\
\text { Includes: institution size or } \\
\text { reputation; number of } \\
\text { colleagues in the department; } \\
\text { presence of doctoral } \\
\text { programme; context of } \\
\text { practice }\end{array}$ \\
\hline $\begin{array}{l}\text { Education and experience } \\
\text { Includes: formal education; } \\
\text { continuing education; research } \\
\text { training; previous research } \\
\text { experience }\end{array}$ & $\begin{array}{l}\text { Guidance and support } \\
\text { from editors }\end{array}$ & $\begin{array}{l}\text { Extrinsic motivation } \\
\text { Includes: extrinsic reward; } \\
\text { desire to build resume; } \\
\text { requirement to publish }\end{array}$ \\
\hline $\begin{array}{l}\text { Personality traits } \\
\text { Includes: self-efficacy; } \\
\text { motivation; creativity; } \\
\text { leadership; positive attitude }\end{array}$ & $\begin{array}{l}\text { Impact of family and } \\
\text { personal relationships }\end{array}$ & $\begin{array}{l}\text { Positive organisational } \\
\text { climate } \\
\text { Includes: supportive } \\
\text { leadership; research valued by } \\
\text { the organization; culture of } \\
\text { research }\end{array}$ \\
\hline \multirow[t]{2}{*}{$\begin{array}{l}\text { Professional commitment } \\
\text { to research } \\
\text { Includes: making research and } \\
\text { writing a priority; } \\
\text { participation in research- } \\
\text { related activities; relevant and } \\
\text { interesting research topic; } \\
\text { opportunity to positively } \\
\text { affect practice; connection to } \\
\text { teaching }\end{array}$} & $\begin{array}{l}\text { Mentoring } \\
\text { Includes: informal and formal } \\
\text { mentoring; supervising } \\
\text { students; being a mentor; } \\
\text { being mentored }\end{array}$ & $\begin{array}{l}\text { Time } \\
\text { Includes: autonomy over work } \\
\text { schedule; balance between } \\
\text { responsibilities; release time; } \\
\text { teaching load }\end{array}$ \\
\hline & $\begin{array}{l}\text { Peer support } \\
\text { Includes: peer mentoring; } \\
\text { writing support groups; } \\
\text { seminar series }\end{array}$ & \\
\hline
\end{tabular}

Table 1: Success factors identified in the literature. 
Once factors had been identified through textual analysis, they were counted in order to determine which were most prevalent in the literature. Across all 121 papers, the most prevalent factors noted were education and experience, time, access to and use of resources, mentoring, and professional commitment to research. Of the total papers related to librarians, the most prevalent factors were time, education and experience, access to and use of resources, and peer support. Of the total papers related to non-librarians, the most prevalent factors mentioned were professional commitment to research, mentoring, education and experience, and access to and use of resources.

Looking more specifically at the 42 papers that presented findings from empirical research studies which explored a direct relationship between success factors and research productivity, many of the factors which were common in the overall body of literature continued to prevail. There were, however, a few changes in the dominant factors discussed. Table 2 provides a summary of the most prevalent factors explored within this subset of the literature (see the Appendix for the list of articles included in this subset).

\begin{tabular}{|c|c|c|c|c|}
\hline Category & $\begin{array}{l}\text { Factor contributing } \\
\text { to success }\end{array}$ & $\begin{array}{l}\text { Number of } \\
\text { studies } \\
\text { (42 total) }\end{array}$ & $\begin{array}{l}\text { Librarian } \\
\text { studies } \\
\text { (11 total) }\end{array}$ & $\begin{array}{l}\text { Non- } \\
\text { librarian } \\
\text { studies } \\
\text { (31 total) }\end{array}$ \\
\hline \multirow[t]{3}{*}{$\begin{array}{l}\text { Individual } \\
\text { Attributes }\end{array}$} & $\begin{array}{l}\text { Education and } \\
\text { experience }\end{array}$ & 27 & 8 & 19 \\
\hline & $\begin{array}{l}\text { Professional } \\
\text { commitment to } \\
\text { research }\end{array}$ & 21 & 2 & 19 \\
\hline & Personality traits & 20 & 3 & 17 \\
\hline $\begin{array}{l}\text { Peers and } \\
\text { Community }\end{array}$ & Mentoring & 19 & 2 & 17 \\
\hline \multirow{4}{*}{$\begin{array}{l}\text { Institutional } \\
\text { Structures } \\
\text { and } \\
\text { Supports }\end{array}$} & Time & 22 & 5 & 17 \\
\hline & $\begin{array}{l}\text { Positive organisational } \\
\text { climate }\end{array}$ & 20 & 6 & 14 \\
\hline & $\begin{array}{l}\text { Access to and use of } \\
\text { resources }\end{array}$ & 18 & 4 & 14 \\
\hline & Extrinsic motivation & 18 & 5 & 13 \\
\hline
\end{tabular}

Table 2: Most prevalent factors that contribute to research success identified in 42 empirical research studies exploring success factors and productivity. 
Both librarians and non-librarians often researched education and experience; this factor was the most studied overall with more than half of the librarian and nonlibrarian papers considering this factor.

For librarians, there is very little research that explores a direct relationship between specific factors and research success. For example, time is the factor most discussed in general, but only five empirical research studies examined time as a contributing factor to research success. Those five studies focused on release time (sabbaticals or research leaves), while studies of non-librarians focused on other aspects of time, such as time allocation.

In addition, some factors which were frequently explored by the research literature of other disciplines have been only rarely explored in the context of librarians. For example, professional commitment to research was examined in only two librarian studies, but in 19 studies related to non-librarians. Likewise, mentoring was examined in two librarian studies but in 17 related to nonlibrarians. The content analysis also identified factors, such as collaboration, community, and guidance and support from editors, that have been not been explored at all in the library literature, but have been researched for nonlibrarians.

\subsection{Studies measuring a direct relationship between factors and research productivity}

Of the 42 research papers that explored a direct relationship between success factors and productivity, 30 studies (seven librarian and 23 non-librarian) attempted to measure the impact of different factors on individual research productivity. Twenty-six (26) of these, including all seven librarian studies, used surveys as the data collection tool, with sample sizes ranging from $n=55$ to $\mathrm{n}=10,000$ and response rates ranging from $6 \%$ to $92 \%$. Four studies analyzed data sets, one study was a systematic review, and one study consisted of both a survey and analysis of a data set. Studies represented geographically diverse areas and populations.

Further analysis was conducted on these 30 studies in order to determine the nature of the measured effect of each factor on research productivity. Some factors were determined by the researchers in these studies to have no measurable effect, and some were found to have a measured positive effect on research productivity. While some researchers reported this positive effect in terms of statistical significance, others reported the effect in more descriptive and qualitative terms. For the current analysis of the factors identified as having the greatest positive effect on research productivity, the authors considered the findings as they were presented in each article; that is, rather than re-analysing the data sources across all 30 articles, the researchers' conclusions were used as the data source.

Within the category of Individual Attributes, education and experience and professional commitment to research were the factors most often reported by authors to have the most positive effect on research productivity. Twenty of the 24 studies that considered factors in the Individual Attributes category were nonlibrarian studies. Only four librarian studies measured the effect of education and 
experience, and these studies' positive findings were in keeping with the nonlibrarian studies that examined this factor. In non-librarian studies, the research on education and experience focused on formal education, such as the degree received and prestige of degree granting institution. In contrast, librarian studies addressed not only formal education, including holding a second masters or doctoral degree (Burlingame and Repp, 1982) and content and location of the MLIS degree, but also informal education such as continuing education opportunities (Fenske and Dalrymple, 1992).

Eight studies measured the effect of professional commitment to research on research productivity and all but one found that the factor had a positive impact. However, only one study measured the impact of professional commitment to research for librarians (Burlingame and Repp, 1982). In Burlingame and Repp's study, they examined the aspect of professional commitment to research that pertains to having the opportunity to affect practice positively. They found that academic librarians who had authored research were more likely to report that publication was an important or very important factor in contributing to the quality of library service, than those who had not published.

Within the category of Peers and Community, mentoring was the only factor that authors identified as showing a positive effect on research productivity. All 12 of the papers that measured the effect of mentoring were focused on non-librarian contexts. Most often the positive effect of mentoring was distilled down to simply the presence of a mentor, but some studies identified more specific aspects of mentoring such as ease of finding a mentor, how influential the mentor was, whether the subjects themselves were mentors, and mentors who advised others in relation to research. A systematic review of mentoring in academic medicine identified several ways in which mentoring affected research productivity, including increased self-confidence for mentees, increased time devoted to research, and, again, simply having a mentor (Sambunjak, Straus and Marušić, 2006).

In the final category of Institutional Structures and Supports, the two factors that demonstrated the greatest positive effect on research productivity were time and access to and use of resources. While articles most often framed the factor of time in terms of availability of release time to dedicate to research, in some nonlibrarian studies time was measured in relation to teaching load and administrative responsibilities. Sixteen of the 30 studies measured the impact of time on research productivity. While 12 of these studies found that the availability of time had a positive effect on research productivity, four studies did not find time to have an effect on research productivity. The two librarian studies that measured the effect of time on research productivity reported that release time for research was a strong predictor of research productivity.

The effect of access to and use of resources on research productivity was measured in 13 studies, two of which were within the context of librarians. All 13 studies found that access to and use of resources had a positive effect on research productivity; the inclusion of the aspect of "funding from institutions" in this factor may have contributed to the overwhelming positive effect. Two librarian studies identified that access to and use of resources had a strong effect on 
research productivity (Fenske and Dalrymple, 1992; Havener and Stolt, 1994). Fenske and Dalrymple's (1992) survey found that institutional support was a major contributing factor to academic health librarians' research productivity; their description of "institutional support" included identification of funding sources and several forms of staff support such as statistical consulting, literature searching, data collection, data analysis, and clerical support. In their survey, Havener and Stolt (1994) found that while only a small fraction of librarians from Oklahoma reported receiving financial support from their institution, those who did had a significantly higher publication rate.

In summary, the factors that showed the most positive effect on research productivity, as reported by the authors of the 30 papers that measured a direct relationship between factors and productivity, were education and experience, professional commitment to research, mentoring, time, and access to and use of resources. While these factors were also all commonly studied, as noted in Table 2 , there were other factors that were frequently studied but those papers' findings do not reveal a consistently positive effect on research productivity. For example, some papers reported that positive organisational climate had a positive effect on research productivity, but others found no significant effect.

\section{Discussion}

This analysis of the literature on research productivity identified sixteen different factors, which fell into three broad, overarching categories detailing different types of success factors. The categories and specific factors require further evaluation in order to determine their contribution to academic librarians' success in conducting and disseminating scholarly research.

The three overarching categories of success factors - Individual Attributes, Peers and Community, and Institutional Structure and Supports - are wide-reaching and encompass qualities and characteristics of the individual, their peer networks, and the institution in which they work. This range of factors, in and of itself, underpins the complexity of the relationship between the factors and research productivity; it is likely that research productivity depends, to varying degrees, on several factors.

The analysis of empirical research studies that aimed to explore a direct relationship between factors and research success highlighted five factors that showed the most positive effect on research productivity within and outside of LIS: education and experience, professional commitment to research, mentoring, time, and access to and use of resources. With the exception of professional commitment to research, these factors align well with the resources and supports that have been developed by libraries and are noted in the literature (such as writing groups, opportunities for research skills development, research leaves and release time, and funding). However, the relative lack of discussion of professional commitment to research in relation to librarians highlights an important area for further research and may indicate that librarians are overlooking a key factor in research productivity. The lack of consideration and examination of personal commitment to research as a factor in research success may be a result of our focus on barriers that are external to us personally or it may 
be that the lack of an established research culture for librarians means that we focus less on attitudes towards research.

The findings strongly reinforce the need for additional research on these success factors in the context of academic librarians, particularly for factors such as mentoring and professional commitment to research where there is little empirical research in the librarian context. The empirical research studies that were conducted in non-librarian contexts may prove to be useful examples and starting points. Furthermore, in both librarian and non-librarian contexts, there were some factors that were seldom or not at all researched in studies that drew direct relationships between those factors and research productivity, which limits the authors' ability to draw conclusions about the relative importance of these sixteen factors and reinforces the overall need for more research on these success factors.

The analysis of how "research productivity" was operationalised in these research studies revealed that productivity or success in research is itself a complex concept. Almost all of the operational definitions of research productivity included an aspect of dissemination, which is appropriate, since dissemination generally marks the completion of a research endeavour. However, this was not the only measure of productivity. Other measures, such as grants received or design of research projects, reflect that "productivity" can also refer to work that is needed in order to start or continue work on a research endeavour.

There were limitations to the research that should be noted. Firstly, while the authors did attempt to conduct thorough and comprehensive literature searches, they did not take a fully systematic approach to gathering the literature. The authors do not claim to have uncovered all literature across all disciplines on the topic of research productivity. In addition, there was a greater focus on completeness of the librarian literature, resulting in a wider variety of the types of literature that were initially discovered but were not analysed in detail because they were not empirical research articles. When searching the non-librarian literature, the authors were more focused on finding articles that met the criteria of presenting a research study, which is why there were proportionally fewer nonresearch articles in the subset of non-librarian literature. Another limitation relates to coding of articles; the reliability of the coding would have been improved if the initial coding of articles had been done by more than one author. Finally, as noted above, the authors did not independently verify the statistics and significance of the findings of each study that was included - the analysis was based on what the authors of the original studies reported. The aim of this study was to identify possible factors that may contribute to librarians' success in research, so that the authors could do further, more comprehensive research on this topic. The authors believe that these goals were met, and that the findings will contribute to the development of a validated tool for determining the success factors that are most important to librarians.

\section{Conclusion}

This study provided valuable insight into factors for research success that have been examined by librarian and non-librarian researchers. The analysis strongly 
reinforces the need for more research on which factors lead to research success for academic librarians.

This research will give LIS practitioners and researchers a greater understanding of the factors that contribute to librarians being successful and productive researchers. This can in turn help the LIS community to put in place the most effective supports and resources and gather more evidence about the effectiveness of the supports that are currently available. While librarians outside of Canada and the United States may not be required to do research, the increasing focus on a culture of assessment and evidence based library and information practice within libraries reinforces the need to build an environment where librarians are situated to participate successfully in research endeavours.

This research can assist library managers as they support those who need to produce research, as well as individual librarians as they reflect on the factors that may have the most impact on their success as researchers.

The authors will use the information gained from this review to inform future phases of their research project on academic librarians' research success. The next phase will be to create a validated research tool to measure the relationship between the factors identified in this review and librarians' research productivity, distribute the tool, and analyze the resulting data. The end result should be a more robust, evidence-based understanding of factors that contribute to librarians' success in their research endeavours.

\section{References}

Black, W.K. and Leysen, J.M. (1994) Scholarship and the academic librarian, College and Research Libraries, 55(3), 229-241.

Brown, J.M. (2001) Time and the academic librarian, portal: Libraries and the Academy, 1(1), 59-70.

Burlingame, D. F. and Repp, J. (1982) Factors associated with academic librarians' publishing in the '70s: Prologue for the '80s. In: Kathman, M. D. and Massman, V. F. (eds.) Options for the 80s: Proceedings of the Second National Conference of the Association of College and Research Libraries. Greenwood, Conn.: JAI Press. 395-404.

Campbell, K., Ellis, M. and Adebonojo, L. (2012) Developing a writing group for librarians: the benefits of successful collaboration, Library Management, 33(1/2), $14-21$.

Cohen, J. G., Sherman, A. E., Kiet, T. K., Kapp, D. S., Osann, K., Chen, L., O'Sullivan, P. S. and Chan, J. K. (2012) Characteristics of success in mentoring and research productivity: a case-control study of academic centers, Gynecologic Oncology, 125(1), 8-13.

Edwards, P. M., Jennerich, E. Z. and Ward, J. L. (2009) Supporting a culture of library research at the University of Washington Seattle. In: Connor, E. (ed.) An introduction to staff development in academic libraries. New York: Routledge. 
$77-89$.

Exner, N. and Houk, A. H. (2010) Starting the write way: comparing two library scholarly development programs, Library Leadership and Management, 24(4), 178-182.

Fallon, H. (2012) Using a blended group learning approach to increase librarian motivation and skills to publish, New Review of Academic Librarianship, 18(1), $7-25$.

Fennewald, J. (2008) Research productivity among librarians: factors leading to publications at Penn State, College and Research Libraries, 69(2), 104-116.

Fenske, R. E. and Dalrymple, P. W. (1992) Factors influencing research productivity among health sciences librarians, Bulletin of the Medical Library Association, 80(4), 353-360.

Fink, A. (2010) Conducting research literature reviews: from the Internet to paper. 3rd ed. Thousand Oaks: Sage Publications.

Flaspohler, M. R. (2009) Librarian sabbatical leaves: do we need to get out more?, Journal of Academic Librarianship, 35(2), 152-161.

Fox, D. (2007) Finding time for scholarship: a survey of Canadian research university librarians, portal: Libraries and the Academy, 7(4), 451-462.

Grant, M. J., Munro, W., McIsaac, J. and Hill, S. (2010) Cross-disciplinary writers' group stimulates fresh approaches to scholarly communication: a reflective case study within a higher education institution in the north west of England, New Review of Academic Librarianship, 16(Suppl.1), 44-64.

Hall, H. (2010) Promoting the priorities of practitioner research engagement, Journal of Librarianship and Information Science, 42(2), 83-88.

Havener, W. M. and Stolt, W. A. (1994) The professional-development activities of academic librarians: does institutional support make a difference, College and Research Libraries, 55(1), 25-36.

Hill, J. S. (1994) Wearing our own clothes: librarians as faculty, Journal of Academic Librarianship, 20(2), 71-76.

Jacobs, H. L. M. and Berg, S. A. (2013) By librarians, for librarians: building a strengths-based institute to develop librarians' research culture in Canadian academic libraries, Journal of Academic Librarianship, 39(3), 227-231.

Kennedy, M. R. and Brancolini, K. R. (2012) Academic librarian research: a survey of attitudes, involvement, and perceived capabilities, College and Research Libraries, 73(5), 431-448.

Library and Information Science Research Coalition (2012). URL:

http://lisresearch.org/ [accessed 03.12.14].

Meadows, K. N., Berg, S. A., Hoffmann, K., Torabi, N. and Gardiner, M. M. (2013) A needs-driven and responsive approach to supporting the research endeavours of academic librarians, Partnership: the Canadian Journal of Library and Information Practice and Research, 8(2). 
McBain, I., Culshaw, H. and Walkley Hall, L. (2013) Establishing a culture of research practice in an academic library: an Australian case study, Library Management, 34(6/7), 448 - 461.

McNicol, S. (2002) LIS researchers and practitioners: creating a research culture. Library and Information Research [online], 26(83). URL:

http://www.lirgjournal.org.uk/lir/ojs/index.php/lir/article/view/134 [accessed 8.3.15].

Neville, T. M. and Henry, D. B. (2007) Support for research and service in Florida academic libraries, Journal of Academic Librarianship, 33(1), 76-93.

Paul, S., Stein, F., Ottenbacher, K. J. and Liu, Y. (2002) The role of mentoring on research productivity among occupational therapy faculty, Occupational Therapy International, 9(1), 24-40.

Powell, R. R., Baker, L. M., and Mika, J. J. (2002) Library and information science practitioners and research, Library and Information Science Research $\mathbf{2 4}$, 49-72.

Sambunjak, D., Straus, S. E. and Marušić, A. (2006) Mentoring in academic medicine: a systematic review, Journal of the American Medical Association, 296(9), 1103-1115.

Sassen, C., and Wahl, D. (2013) Fostering research and publication in academic libraries, College and Research Libraries, 75(4), 458-491.

Schrader, A. M., Shiri, A. and Williamson, V. (2012) Assessment of the research learning needs of University of Saskatchewan librarians: a case study, College and Research Libraries, 73(2), 147-163.

Spring, H. (2014) An investigation into the barriers to and priorities for research engagement in health librarianship, International Journal of Health Information Management Research, 2(1), 58-79.

\section{Open access and copyright}

Library and Information Research is an open access journal. A freely available copy of this paper may be downloaded from the journal's website:

http://www.lirgjournal.org.uk.

Copyright and associated moral rights in works published in Library and Information Research are retained by the author(s) but this paper may be used freely, with proper attribution, in educational and other non-commercial settings. 